\title{
Microbiological and Physicochemical Qualities of Moo Som (Traditional Thai Fermented Meat) Inoculated with Lactic Acid Bacteria Starter
}

\author{
Pussadee TANGWATCHARIN*, Jiraroj NITHISANTAWAKHUP and \\ Supaluk SORAPUKDEE
}

Department of Animal Production Technology and Fisheries, Faculty of Agricultural Technology, King Mongkut's Institute of Technology Ladkrabang, Bangkok 10520, Thailand

('Corresponding author's e-mail: putang3009@hotmail.com)

Received: 21 March 2018, Revised: 7 November 2018, Accepted: 10 December 2018

\begin{abstract}
The effects of different strains of lactic acid bacteria (LAB) inoculation on the fermentation rates and qualities of moo som, a traditional Thai fermented pork, were evaluated. Lactobacillus plantarum KL102 (spontaneous starter) and L. plantarum TISIR543 (commercial starter) were used as starter cultures in the production of moo som. The decreased amounts of Staphylococcus aureus and coliforms in moo som inoculated with L. plantarum KL102 were at faster rates than those in Moo som inoculated with L. plantarum TISIR543. However, the final products of moo som inoculated with both LAB starters did not find $S$. aureus or and coliform loadings. Inoculation of both LAB starters could control growth of yeast in samples during fermentation. Furthermore, both starter cultures exhibited a higher rate of fermentation than the control (without inoculum), as demonstrated by the faster rate $\mathrm{pH}$ drop and acid production $(p<0.05)$ during fermentation, while the fermentation of all samples were completed within 3 d. Due to higher acid production rate, texture, and especially hardness, gumminess and chewiness of inoculated moo som were higher than control moo som in the final products $(p<0.05)$. From the results, the inoculation of LAB starter was more beneficial in color and in overall sensory evaluation $(p<0.05)$. The overall quality was positively correlated with the color, odor, and texture of moo som $(p<0.01)$. Based on microbiological and physicochemical qualities and sensory evaluation, KL102 is a potential LAB starter for moo som production.
\end{abstract}

Keywords: Moo som, Traditional Thai fermented meat, LAB starter, Lactobacillus plantarum

\section{Introduction}

Moo som is a traditional Thai fermented pork cuisine and is generally consumed in the northeast region of Thailand. The main ingredients of moo som are cut, sliced, diced, or stripped pork, cooked rice, chopped garlic, salt, and nitrite. A raw mixture is completely wrapped in banana leaves or packed plastic casings and then held at room temperature for $3-5 \mathrm{~d}$. This product is consumed both with and without cooking [1]. Traditional fermented meat cuisines are related to the participation of lactic acid bacteria (LAB) which commonly exist in raw materials. This process supports the growth of spontaneous microflora, which influences the texture, flavor, nutritional qualities, safety, and other properties of fermented meat [2]. Traditional Thai fermented pork cuisines use natural acid production; the fermentation is decontrolled, which affects the organoleptic quality and safety of the final products. Depending on spontaneous microbes of contamination, pathogenic appearance, such as Escherichia coli, Salmonella spp. and Staphylococcus aureus has been estimated to especially present in these cuisines 
with $\mathrm{pH}$ value more than 4.6 [3]. Therefore, for product quality and product safety, an enhanced fermentation process for moo som using a starter culture technology has been advanced.

The starter cultures used in meat fermentation have suited the means to support fermentation rates and the stability of the product. Starter cultures were used to enhance qualities of physicochemistry, microbiology, and sensory characteristics, and to abbreviate the fermentation time in the production of fermented meat. LABs are generally recognized as safe to consume [4,5]. The growth inhibition of unpleasing microorganisms is due to a decrease of $\mathrm{pH}$ value. LAB starters are used in fermented sausage for advantageous technology and hygiene. Generally, these starters are used to acidify the fermented sausage to control growth of spoilage and pathogenic bacteria under low $\mathrm{pH}$ conditions [6]. Due to inoculation with lactobacilli in traditional Thai fermented meat sausage, a sharp decrease of $\mathrm{pH}$ and rapid fermentation rate of product was found [7]. Some previous studies have discussed production of traditional Thai fermented pork sausage inoculated with commercial starter culture such as Lactobacillus curvatus and L. plantarum [5,8,9]. Furthermore, L. plantarum, isolated from traditional Thai fermented sausage, produced pediocin-like bacteria, which should indicate antimicrobial activity against pathogenic Gram-negative bacteria $[10,11]$.

Our previous studies reported that L. plantarum KL102 (KL102) was isolated from traditional Thai fermented meat as a spontaneous starter culture. This bacterium should demonstrate antimicrobial activity against $E$. coli, $S$. Typhimurium $S$. aureus and L. monocytogenes, [12] and survival from gastrointestinal conditions (acidity, pepsin, bile salt, and pancreatin) [13] as a candidate probiotic. The objective of this study was to estimate the quality of microbiology, defined as health safety, physicochemical quality, and sensory acceptability of moo som inoculated with KL102 during fermentation. The effect of KL102 inoculation on qualities of moo som was compared with those of TISIR543 inoculation and without inoculation, as commercial starter and natural fermentation, respectively.

\section{Materials and methods}

\section{Starter culture preparation}

L. plantarum KL102 was previously isolated from traditional Thai fermented meat cuisine as a spontaneous starter culture. Briefly, this strain was a candidate probiotic for its preliminary probiotic functions, including antimicrobial activity against foodborne pathogen [12] and survival from gastrointestinal tract model [13]. L. plantarum TISIR543 as a commercial starter was purchased from the BIOTIC Culture Collection. Each strain was stored at $-20{ }^{\circ} \mathrm{C}$ in de Man, Rogosa, and Sharpe (MRS) broth (Merck, Germany), containing $20 \%$ (v/v) glycerol. Before use, frozen cultures were cross-linked on MRS agar and then incubated anaerobically at $30{ }^{\circ} \mathrm{C}$ for $24 \mathrm{~h}$. Cells were harvested by centrifugation at $6000 \times \mathrm{g}$ at $4{ }^{\circ} \mathrm{C}$ for $10 \mathrm{~min}$ in a Universal $16 \mathrm{R}$ refrigerated centrifuge (Hettich Zentrifugen, Germany), washed, and resuspended in $0.85 \%(\mathrm{w} / \mathrm{v})$ sodium chloride (saline solution). Finally, the cell concentration of each LAB starter was adjusted to $10^{8} \mathrm{cfu} / \mathrm{ml}$ with saline solution by comparing the turbidity of $0.5 \mathrm{McFarland}$. One $\mathrm{ml}$ of $\mathrm{LAB}$ was added in $1 \mathrm{~kg}$ of moo som mixture which contained approximately $10^{5} \mathrm{cfu} / \mathrm{g}$ of inoculum.

\section{Moo som preparation}

The moo som mixture was made from chilled lean pork (postmortem time within $24 \mathrm{~h}$ and $\mathrm{pH}$ values between 5.50 - 5.70) and the ingredients and additives ( $\mathrm{g} / \mathrm{kg}$ lean pork): cooked rice, 65; minced garlic, 65; sugar, 4; erythrobate, 4, sodium tripolyphosphate, 3; sodium chloride, 10, and potassium nitrite, 0.8. Lean pork was stored at $2{ }^{\circ} \mathrm{C}$, cut $(10 \mathrm{~mm}$ wide $\times 20 \mathrm{~mm}$ length $\times 3 \mathrm{~mm}$ thick), and mixed with all ingredients and additives. Three separated batches of moo som were inoculated with different inoculum of L. plantarum (non-inoculum [control], TISIR543 and KL102) at $10^{5} \mathrm{cfu} / \mathrm{g}$ of initial concentration. Each mixture batch was stuffed into plastic casing with a diameter of $30 \mathrm{~mm}$ (approximately $100 \mathrm{~g}$ each) and, after that, sealed completely. All samples were incubated at $30{ }^{\circ} \mathrm{C}$ for 3 $\mathrm{d}$ and then taken for analysis every $1 \mathrm{~d}$. 


\section{Microbiological analysis}

Microbiological analyses were carried out in triplicate during the fermentation for LAB, S. aureus, coliforms, E. coli, Salmonella spp., yeast, and mold. The casings were aseptically removed and $25 \mathrm{~g}$ of moo som was diluted in $225 \mathrm{~mL}$ of saline solution and homogenized in a stomacher bag mixer (Interscience, France). The homogenate was serially diluted with saline solution and $1 \mathrm{~mL}$ of each dilution was grown in different media and duplicate plates. The following media and incubated conditions were used: (1) MRS agar (Merck, Darmstadt, Germany), incubated anaerobically at $30{ }^{\circ} \mathrm{C}$ for $24-48 \mathrm{~h}$ for LAB count [14], (2) potato dextrose agar (Merck, Darmstadt, Germany), incubated at $25{ }^{\circ} \mathrm{C}$ for $3-5 \mathrm{~d}$ for yeast and mold counts, (3) Baird-Parker agar (Merck, Darmstadt, Germany), incubated at $37{ }^{\circ} \mathrm{C}$ for 24 - $48 \mathrm{~h}$, and the coagulase test used for the identification of $S$. aureus colonies for $S$. aureus count [15], and (4) Fluorocult ${ }^{\circledR}$ LMX Broth (Merck, Darmstadt, Germany), incubated at $37{ }^{\circ} \mathrm{C}$ for $24-48 \mathrm{~h}$, and the IMViC test used for the identification of E. coli for estimating the MPN of coliforms and E. coli [16]. Salmonella spp. was estimated in $25 \mathrm{~g}$ according to ISO 6579 [17]. Briefly, $25 \mathrm{~g}$ of sample was aseptically placed into a sterile stomacher bag with a filter that contained $225 \mathrm{~mL}$ of buffered peptone water (BPW; Merck, Darmstadt, Germany) and was incubated at $37^{\circ} \mathrm{C}$ for $18 \mathrm{~h}$ after homogenization by stomacher for $2 \mathrm{~min}$. After pre-enrichment, 0.1 and $1 \mathrm{~mL}$ from the $\mathrm{BPW}$ culture were transferred into Rappaport Vassiliadis Soya broth (RVS; Merck, Darmstadt, Germany) and into Muller-Kauffmann tetrathionate - novobiocin broth (MKTTn; Merck, Darmstadt, Germany), respectively, and these were incubated for $24 \mathrm{~h}$ for primary enrichment at 41.5 and $37{ }^{\circ} \mathrm{C}$, respectively. After incubation, $20 \mu \mathrm{L}$ of these cultures were plated onto bismuth sulfite agar (Merck, Darmstadt, Germany) and xylose lysine deoxycholate agar (XLD; Merck, Darmstadt, Germany). The absence of typical colonies for Salmonella on plates examined after incubation at $37{ }^{\circ} \mathrm{C}$ for $24 \mathrm{~h}$ indicated that the samples were free from Salmonella.

\section{pH value and total acid content determinations}

The homogenates for $\mathrm{pH}$ and total acid content determinations were prepared out of $2 \mathrm{~g}$ of sample and $20 \mathrm{~mL}$ of distilled water. The homogenization of the raw mixture used an Ultra-Turrax IKA (Werke Gmbh \& Co.KG, Germany) at a speed of $8,000 \mathrm{rpm}$ for $60 \mathrm{~s}$. Both determinations were estimated in triplicate for each sample. The $\mathrm{pH}$ determination was taken directly using a $\mathrm{pH}$ meter (Mettler Toledo S20, Switzerland). The homogenate was centrifuged at $3000 \times \mathrm{g}$ for $15 \mathrm{~min}$. The supernatant was filtered through Whatman filter paper No. 4. The filtrate was titrated with $0.1 \mathrm{M}$ sodium hydroxide using phenolphthalein as an indicator. The total acid content was estimated as lactic acid and revealed as a $\mathrm{g} / 100 \mathrm{~g}$ sample [18].

\section{SDS-polyacrylamide gel electrophoresis (SDS-PAGE)}

A sample (3 g) was homogenized in $27 \mathrm{~mL}$ of solution containing $1 \%(\mathrm{w} / \mathrm{v}) \mathrm{SDS}, 8 \mathrm{M}$ urea, and 2 $\%(\mathrm{v} / \mathrm{v}) \beta$-meraptoethanol. The homogenate was incubated at $85{ }^{\circ} \mathrm{C}$ for $60 \mathrm{~min}$ and centrifuged at $10000 \times \mathrm{g}$ for $30 \mathrm{~min}$. The protein concentration of supernatant was determined according to the method of Lowry et al. [19]. SDS-PAGE was evaluated according to the method of Laemmli [20]. Samples were solubilized in SDS-PAGE sample buffer containing $1.5 \mathrm{M} \beta$-meraptoethanol at a ratio of 1:1 (v/v). The solubilized samples were boiled for 3 min. The samples $(20 \mu \mathrm{g})$ were loaded on a gel made of $4 \%$ stacking and $5-20 \%$ gradient separating gels. Electrophoresis was conducted at a constant voltage of $110 \mathrm{~V}$ using a vertical gel electrophoresis unit (Mini-Protean II; Bio-Rad Laboratories, Richmond, CA, USA). After protein separation, bands of protein were stained with $0.125 \%(\mathrm{w} / \mathrm{v})$ Coomassie Brilliant Blue R-250 in $10 \%(\mathrm{w} / \mathrm{v})$ and acetic acid $25 \%(\mathrm{v} / \mathrm{v})$ ethanol. Destaining was performed with $10 \%(\mathrm{w} / \mathrm{v})$ acetic acid and $25 \%(\mathrm{v} / \mathrm{v})$ ethanol.

\section{Released water content determination}

The water released from samples was estimated immediately upon collection of samples and revealed as g/100 g [21]. Samples with casings were weighed (a). After the casing removal, Whatman filter paper No. 4 was used to absorb the water released on the surface, and then samples were reweighed 
http://wjst.wu.ac.th

(b). Thereafter, the empty casings were washed, dried, and weighed (c). The released water was calculated with the following equation:

Released water $(\mathrm{g} / 100 \mathrm{~g})=100 \times([\mathrm{a}-\mathrm{b}]-\mathrm{c}) /(\mathrm{a}-\mathrm{c})$

\section{Color}

The sample color was measured in the CIE L* $a^{*} b^{*}$ mode of CIE using a HunterLab MiniScan EZ 4000L (Hunter Associates Laboratory, USA). The color variations of each sample were measured on the surface of the samples by 3 readings of each 3 location. Color difference $(\Delta \mathrm{E})$ was calculated according to the following equation of AMSA [22]:

$\Delta \mathrm{E}=\left[(\Delta \mathrm{L} *)^{2}+\left(\Delta \mathrm{a}^{*}\right)^{2}+(\Delta \mathrm{b} *)^{2}\right]^{1 / 2}$

\section{Texture profile analysis (TPA)}

Pieces of moo som were cut into cylinders (30 mm diameter $\times 30 \mathrm{~mm}$ height) and placed on the base of the instrument. TPA was estimated using a universal testing machine model 1011 (Instron Engineering Corp., USA) by a cylindrical aluminum probe, $55 \mathrm{~mm}$ inner diameter. TPA textural variables were estimated at normal room temperature with the subsequent testing conditions: crosshead speed was $1 \mathrm{~mm} / \mathrm{s}$ and compressed 2 times to $40 \%$ of their original height. The collection and processing of data were carried out by the Bluehill 2 software (Instron Engineering Corp., USA). TPA analyses were determined and calculated according to the description of Bourne [23]. These determinations were estimated in triplicate for each sample. Hardness $(\mathrm{N})$, cohesiveness (ratio), gumminess $(\mathrm{N})$, springiness (ratio), and chewiness $(\mathrm{N})$ were estimated for the force-time curves generated for each sample.

\section{Sensory evaluation}

The fermented moo som $(\mathrm{pH}<4.6)$ was evaluated for sensory attributes by 30 semi-trained panelists from academic staffs and undergraduate and graduate students of the Faculty of Agricultural Technology, King Mongkut's Institute of Technology Ladkrabang, who regularly consumed traditional Thai fermented meat [24]. The panelists had sensorial experience with moo som. A nine-point hedonic scale, in which a score of $9=$ liked extremely, $5=$ neither liked nor disliked and $1=$ disliked extremely, was used for estimation. Three semicircles of each moo som were served in white small bowls and samples were covered with aluminum foil at normal room temperature. Moo som samples were coded with 3 digit random numbers and exhibited to the panelists. Unsalted cracker and room temperature water were served to panelists to refresh their palates between samples. The panelists evaluated each moo som sample for color, appearance, sour odor, texture, flavor, and overall liking.

\section{Statistical analysis}

The data were obtained in triplicate and presented as means \pm standard deviations. The treatments for the study of moo som during fermentation had a $3 \times 4$ factorial in completely randomized design (CRD). The factors were different inoculum of L. plantarum (control, TISIR543 and KL102) and fermentation time $(0,1,2$ and $3 \mathrm{~d})$. For moo som at the end of fermentation, all treatments had CRD in which the factor was different inoculum of L. plantarum. All results were based on analysis of variance (ANOVA) by SAS 9.0 software (SAS Institute Inc., USA). Multiple comparisons were accomplished for the data using Duncan's multiple range tests at $p<0.05$. Pearson's correlation coefficients were carried out to determine the relationship among parametric variables. 
http://wjst.wu.ac.th

\section{Results and discussion}

Effect of inoculation KL102 on LAB count and microbiological quality of moo som during fermentation

LAB count indicated significant differences between moo som inoculated with starter cultures and control (without inoculation) only at day 0 and day 1 of fermentation (Figure 1A). Due to relatively low spontaneous LAB counts in control moo som before fermentation (approximately $4 \log \mathrm{cfu} / \mathrm{g}$ ), the inoculations of TISIR543 or KL102 (approximately $5 \mathrm{log} \mathrm{cfu} / \mathrm{g}$ ) could increase LAB counts. The microbiological quality of moo som during fermentation was directly implicated by these inoculations. The spontaneous microflora in fermented sausages are obtained mainly from the raw materials [5]. According to this study, LAB count in ground lean pork was approximately $4 \log \mathrm{cfu} / \mathrm{g}$ (data not shown). The LAB counts reached maximum levels of $9 \log \mathrm{cfu} / \mathrm{g}$ after $1 \mathrm{~d}$ and $2 \mathrm{~d}$ for both moo som inoculated with LAB starter and control, respectively. Thereafter, LAB counts were constant through to the end of fermentation. In moo som, a rapid growth of $\mathrm{LAB}$ decreasing $\mathrm{pH}$ to below 4.6 within $3 \mathrm{~d}$ is essential against growth of spoilage and pathogenic bacteria [25].
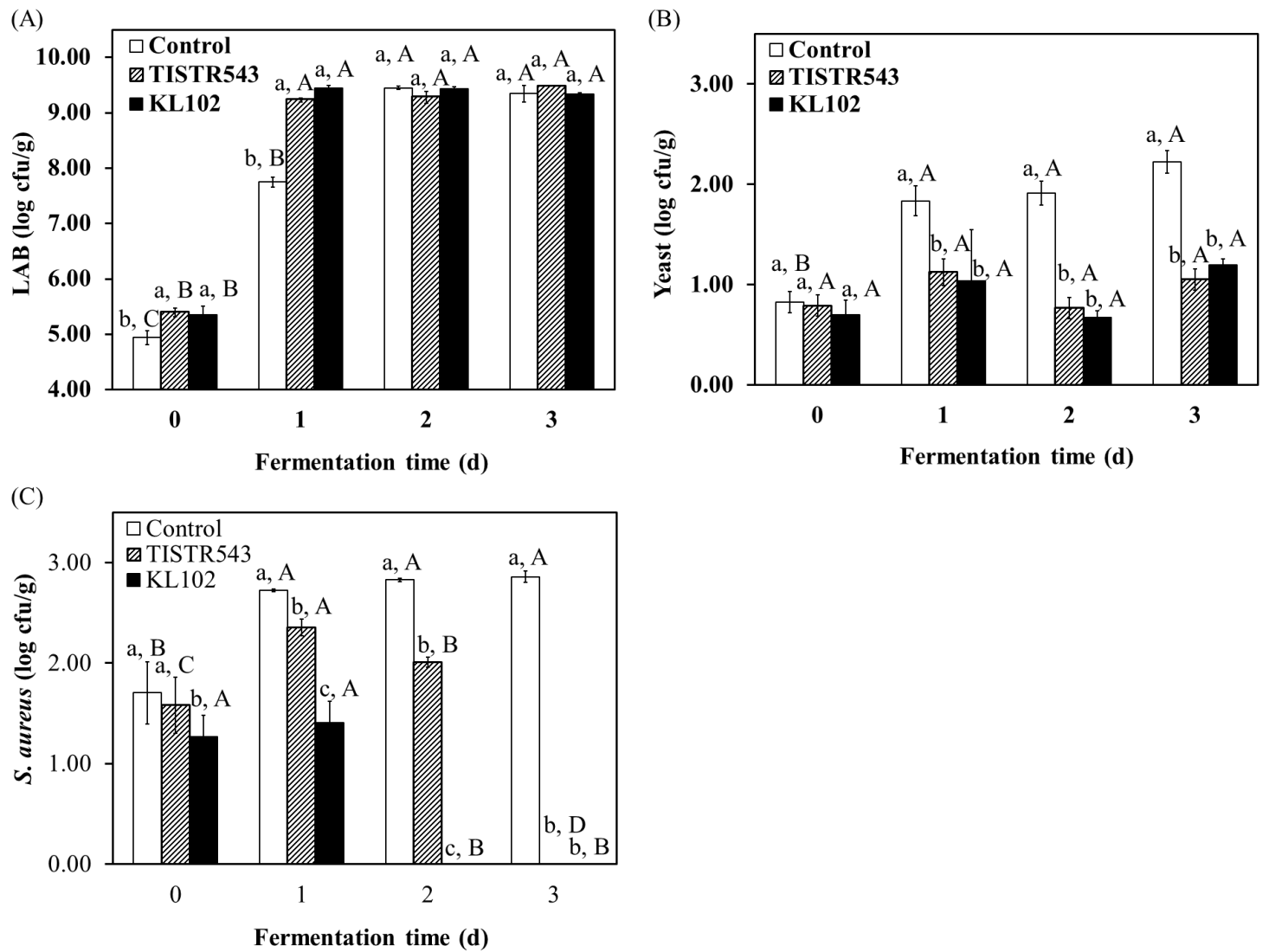

Figure 1 LAB (A), yeast (B), and $S$. aureus (C) counts (log cfu/g) of moo som inoculated with different inoculum of L. plantarum (non-inoculum [control], TISTR543, and KL102) during fermentation. Different lowercase letters within the same fermentation time indicate significant differences in sample ( $p$ $<0.05)$. Different uppercase letters within the same sample indicate significant differences in fermentation time $(p<0.05)$. 
http://wjst.wu.ac.th

The microbiological quality of moo som during fermentation showed that the spontaneous yeast counts in all samples before fermentation were less than $2 \log \mathrm{cfu} / \mathrm{g}$ (Figure 1B). Thereafter, yeast counts in control moo som increased until the final product at the level of $3 \mathrm{log} \mathrm{cfu} / \mathrm{g}$. The growth of yeast in control moo som was due to $\mathrm{pH}$ values in moo som $(\mathrm{pH} 4.3-5.3)$ as optimum $\mathrm{pH}$ of yeast growth (pH 4 6) [26]. On the other hand, yeast counts in moo som inoculated with KL102 or TISIR543 was constant throughout the fermentation. According to the report of Zagorec and Champomier-Vergès [27], inoculation of $L$. sakei could control the growth of yeast in fermented sausages during fermentation. Similarly, S. aureus counts presented relevant significant differences between both moo som inoculated with LAB starter and control (Figure 1C). This count in moo som inoculated with KL102 and TISIR543 showed a decrease after 2 and $3 \mathrm{~d}$ of fermentation, respectively, until the final product at lower than $1 \mathrm{log}$ $\mathrm{cfu} / \mathrm{g}$. In contrast, these counts in control moo som showed an increase after $1 \mathrm{~d}$ of fermentation and then remained constant until the final product at roughly $3 \mathrm{log} \mathrm{cfu} / \mathrm{g}$. In terms of coliform loading, KL102 or TISIR543 inoculation could control growth of this bacteria group; coliform loading in final products were lower than $3 \mathrm{MPN} / \mathrm{g}$ (Table 1). However, E. coli loading in all samples before fermentation were lower than $3 \mathrm{MPN} / \mathrm{g}$. Thereafter, slight growth of $E$. coli was found after $1 \mathrm{~d}$ of fermentation, but its loading in all final products was lower than $3 \mathrm{MPN} / \mathrm{g}$. Our previous studies showed that KL102 has antimicrobial activity against $S$. aureus and E. coli [12]. Similarly, TISIR543 inhibited growth of $S$. aureus and E. coli (data not show). Furthermore, L. plantarum produced many metabolic products as antimicrobial potential (short-chain organic acid, organic acid, hydrogen peroxide, carbon dioxide, diacetyl, and bacteriocin) [28]. Additionally, mold and Salmonella spp. loadings in all samples (36 samples) were lower than 1 log $\mathrm{cfu} / \mathrm{g}$, and not detectable in $25 \mathrm{~g}$, respectively, during the fermentation. For microbiological quality, the results showed that a decrease of $S$. aureus and coliform loading in moo som inoculated with KL102 was faster than those in moo som inoculated with TISIT543.

\section{Effect of inoculation KL102 on physicochemical quality of moo som during fermentation pH value and total acid content}

The results of $\mathrm{pH}$ value and total acid content of moo som inoculated with TISIR543, KL102, and control were taken during the fermentation process (Figure 2A). Within the first day of fermentation significantly high $(p<0.01)$ lower $\mathrm{pH}$ values were found in moo som inoculated with TISIR543 and KL102. For the final products $(\mathrm{pH}<4.6)$, all samples did not differ significantly $(p>0.05)$ in term of the $\mathrm{pH}$ value. The rapid decrease of $\mathrm{pH}$ in initial fermentation was attributed to an increase in LAB counts and total acid content ( $r=-0.915, p<0.01$ and $r=-0.913, p<0.01$, respectively). Commonly, homo- or heterofermentative LABs produce lactic acid as their major end product of fermentation via the EmbdenMeyerhof pathway (glycolysis) or the phosphoketolase pathway (phosphogluconate pathway), respectively [29]. In the final product, total acid content was significantly $(p<0.05)$ higher in moo som inoculated with TISIR543 (Figure 2B).

Table 1 Coliform and E. coli loadings (MPN/g) of moo som inoculated with TISIR543 and KL102 during fermentation ${ }^{1}$.

\begin{tabular}{lcccc}
\hline $\begin{array}{l}\text { Bacterial } \\
\text { indicators }\end{array}$ & $\begin{array}{c}\text { Fermentation time } \\
\text { (d) }\end{array}$ & Control & TISIR543 & KL102 \\
\hline Coliforms & 0 & $9.4-38$ & $9.2-14$ & $9.2-35$ \\
& 1 & $>1,100$ & $>1,100$ & $>1,100$ \\
& 2 & $>1,100$ & $20-43$ & $<3$ \\
& 3 & $>1,100$ & $<3$ & $<3$ \\
\hline E. coli & 0 & $<3$ & $<3$ & $<3$ \\
& 1 & $460-1,100$ & $<3-9$ & $<3$ \\
& 2 & $<3$ & $<3$ & $<3$ \\
\hline
\end{tabular}

\footnotetext{
${ }^{1}$ Values are data from triplicate determinations.
} 

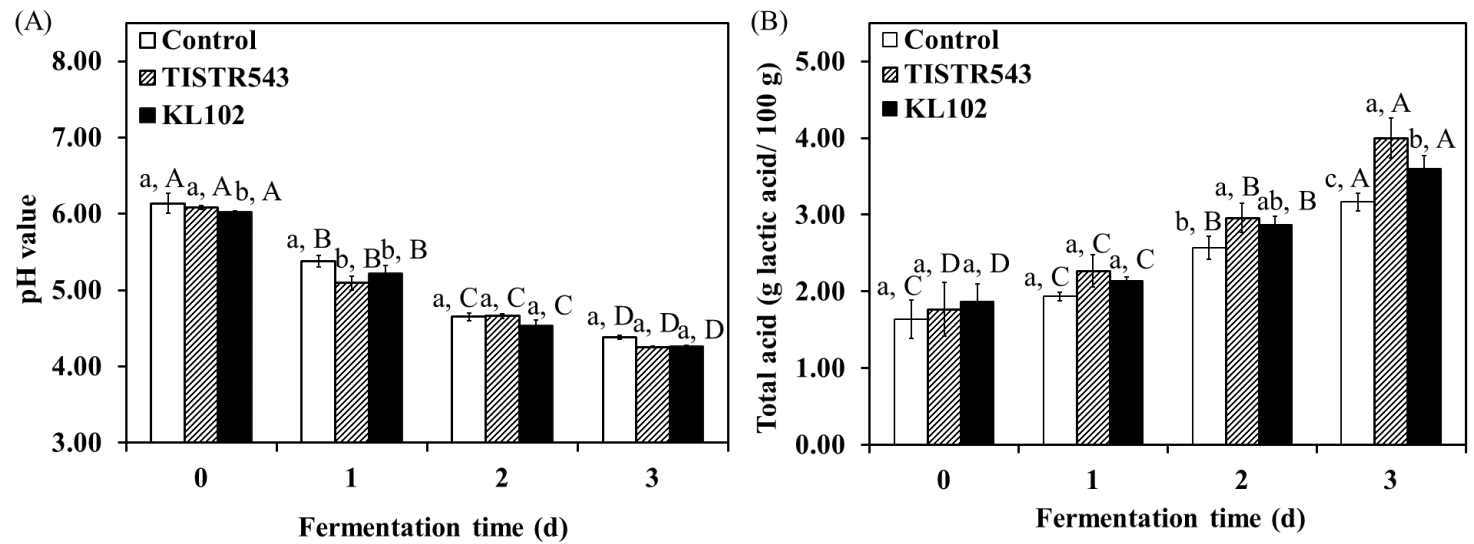

Figure $2 \mathrm{pH}$ values (A) and total acid (B) of moo som inoculated with different inoculum of L. plantarum (non-inoculum [control], TISTR543, and KL102) during fermentation. Different lowercase letters within the same fermentation time indicate significant differences in sample $(p<0.05)$. Different uppercase letters within the same sample indicate significant differences in fermentation time $(p<0.05)$.

\section{Proteolysis}

Electrophoretic patterns of proteins in the raw moo som mixture and in samples inoculated with TISIR543 or KL102 during fermentation indicated an intense degradation of the myofibrillar proteins, especially myosin and actin, throughout the fermentation (Figure 3). No difference in proteolytic activity was found between all samples. In all samples, the intensity of myosin heavy chain (MHC) band decreased with increasing fermentation time. After $1 \mathrm{~d}$ of fermentation, protein with a molecular weight of approximately $160 \mathrm{KDa}$ was found. Actin was markedly degraded after $2 \mathrm{~d}$ of fermentation. MHC was the most sensitive to proteolysis among all muscle proteins, while actin was more resistant to proteolysis [30]. For the results of this study, degradation of actin was to a lower extent than that of MHC. Therefore, it appeared that MHC endured degradation during fermentation, and this could be associated to the moo som characteristic. During fermentation, the $\mathrm{pH}$ value consistently decreased to the acidic range (Figure 2). This acidic condition might favor the hydrolysis of muscle proteins caused by cathepsins. Cathepsins are commonly active at acidic $\mathrm{pH}$ value (usually between $\mathrm{pH} 5.0$ and 5.5). Proteolysis is one of the most considerable biochemical changes appearing during the fermentation of Thai fermented sausage [31, 32]. Generally, proteolysis in muscle appears originally due to the action of cathepsins, in which sarcoplasmic and myofibrillar proteins are broken down [33]. For meat proteins and peptides, proteolytic activity was related to LAB, staphylococci, yeast and molds [34]. The complete hydrolysis of oligopeptides occurs from both endogenous and microbial peptidases [35].

\section{Released water content and color}

Increases in released water contents of moo som inoculated with TISIR543, KL102, and control are reported in Figure 4. In all samples, the released water contents increased with increasing fermentation time $(p<0.05)$. However, during the first $1 \mathrm{~d}$ of fermentation, significantly high $(p<0.05)$ higher released water contents were found in moo som inoculated with TISIR543. At the end of fermentation, released water contents of control moo som were higher than those of moo som inoculated with TISIR543 and KL102 $(p<0.05)$. In addition, no differences in released water content were observed moo som inoculated with different LAB starters $(p>0.05)$. Generally, released water content is associated with water retained in casing and on the surface of product [32]. Moo som with high released water might have muscle proteins with low water holding capacity. During fermentation, protein in moo som endured denaturation induced by acid formation in which a higher amount of released water content was related to their higher total acid content $(r=0.903, p<0.01)$. This was probably due to the protein coagulation or aggregation, which was related to the lower water retained in the fermented meat matrix [36]. Differences 
http://wjst.wu.ac.th

in water retention because of different relative rates of acid induced coagulation and proteolysis may explain the positive relationship found between rates of acidulation and texture development during fermentation [37]. The increase of released water due to the water loss is of economic prominence. The water is considerable for the texture and accumulated exudation is also not pleasing to the consumer [36].

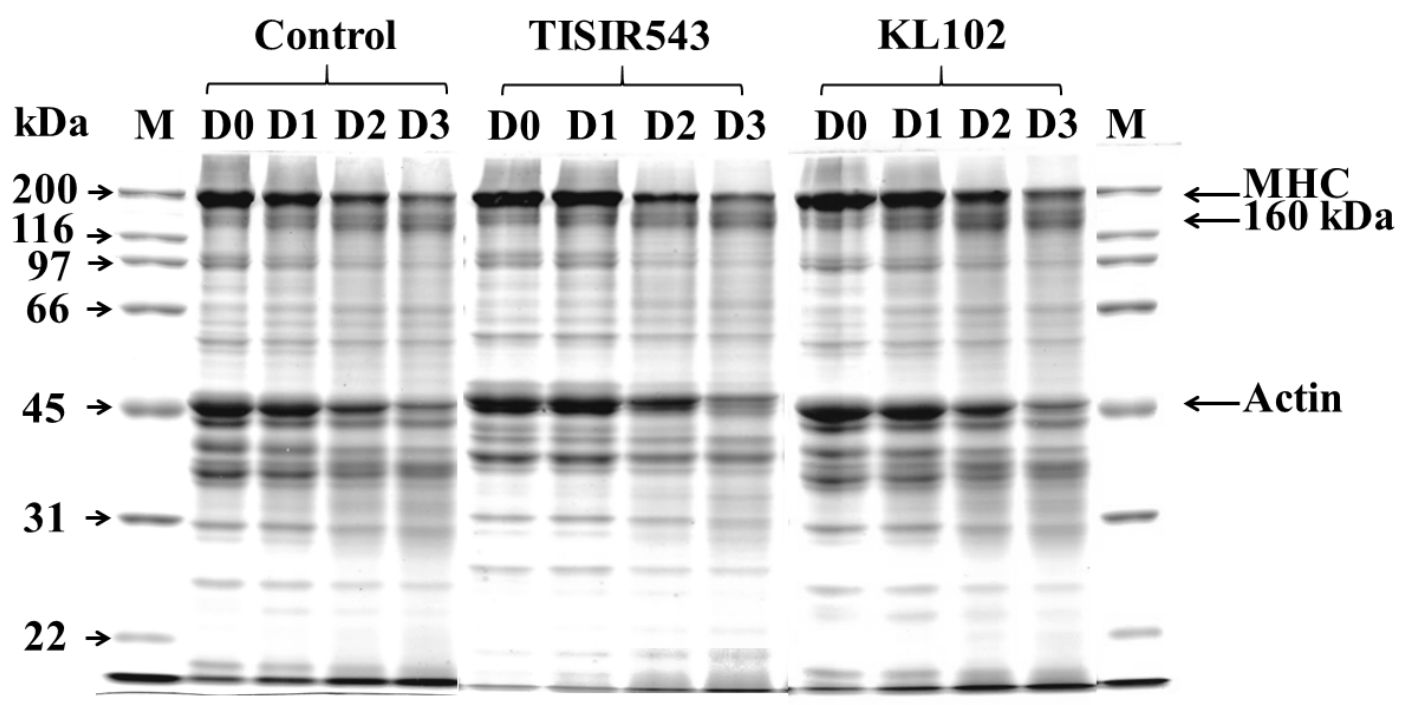

Figure 3 SDS-PAGE pattern of proteins in moo som inoculated with different inoculum of $L$. plantarum (non-inoculum [control], TISTR543, and KL102) during fermentation. D is day of moo som fermentation and $\mathrm{M}$ is the range of the marker.

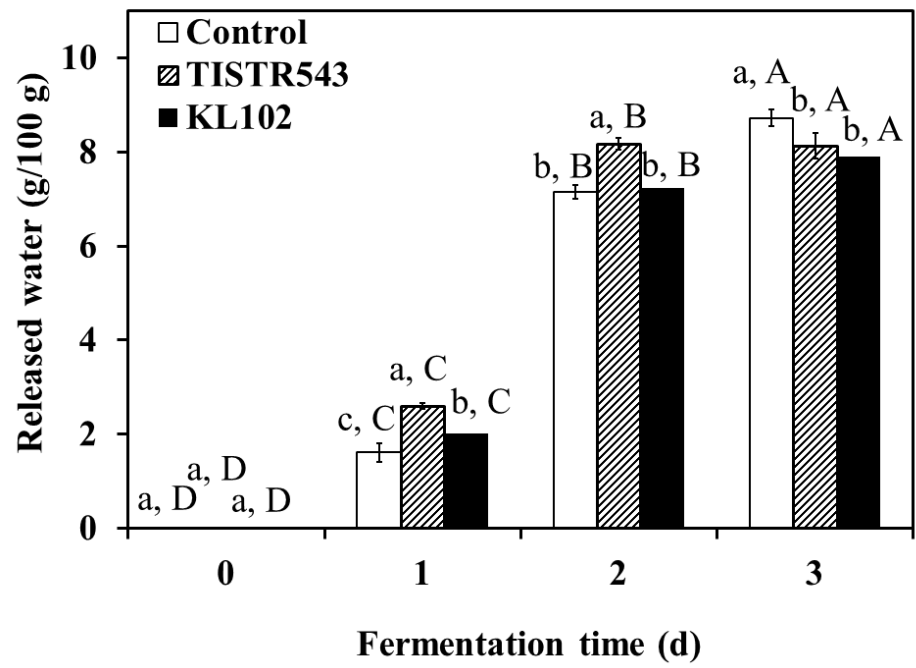

Figure 4 Released water (g/100 g) of moo som inoculated with different inoculum of L. plantarum (noninoculum [control], TISTR543, and KL102) during fermentation. Different lowercase letters within the same fermentation time indicate significant differences in sample $(p<0.05)$. Different uppercase letters within the same sample indicate significant differences in fermentation time $(p<0.05)$. 

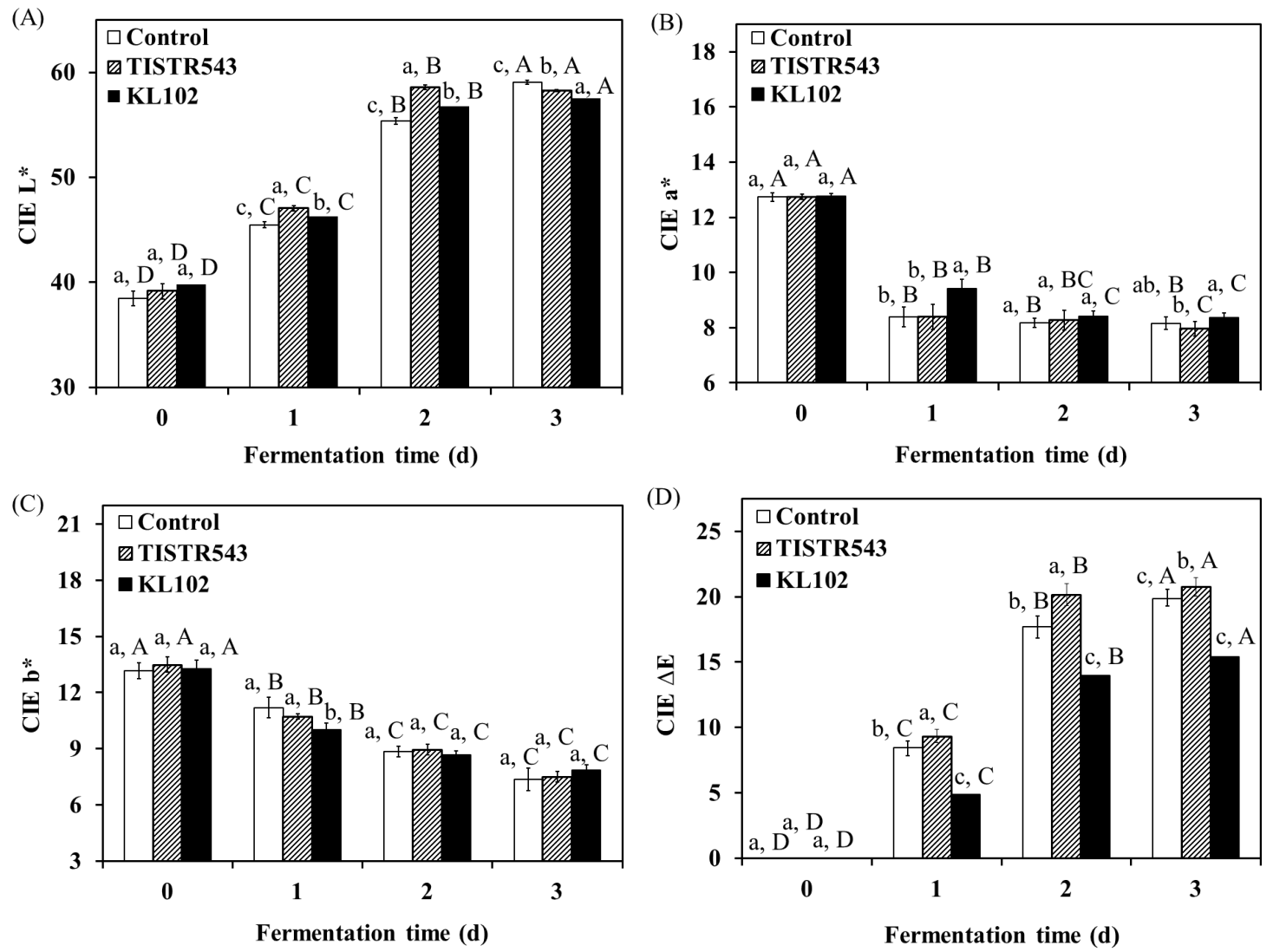

Figure 5 CIE $L^{*}(\mathrm{~A}), \mathrm{a}^{*}(\mathrm{~B}), \mathrm{b}^{*}(\mathrm{C})$, and $\Delta \mathrm{E}$ (D) of moo som inoculated with different inoculum of $L$. plantarum (non-inoculum [control], TISTR543, and KL102) during fermentation. Different lowercase letters within the same fermentation time indicate significant differences in sample $(p<0.05)$. Different uppercase letters within the same sample indicate significant differences in fermentation time $(p<0.05)$.

CIE $L^{*}, a^{*}, b^{*}$, and $\Delta E$ values of moo som during fermentation are portrayed in Figure 5. In all samples, CIE L* values (lightness) increased during the first $1 \mathrm{~d}$ of fermentation and then continuously increased through to the end of fermentation $(p<0.01)$. Lower CIE a* values depicted a decrease in redness during the first $1 \mathrm{~d}$ of fermentation $(p<0.01)$ and then slightly decreased through to the end of fermentation $(p<0.05)$. CIE $\mathrm{b}^{*}$ values (yellowness) rapidly decreased during the first $2 \mathrm{~d}$ of fermentation $(p<0.01)$ and then slightly decreased through to the end of fermentation $(p<0.05)$. Changing of CIE L*, $\mathrm{a}^{*}$, and $\mathrm{b}^{*}$ values affected a rapid increase in CIE $\Delta \mathrm{E}$ values or color difference during fermentation $(p<$ $0.05)$ in which a higher amount of CIE $\Delta \mathrm{E}$ values were related to their higher CIE $\mathrm{L}^{*}$ and lower CIE $\mathrm{a}^{*}$ and $\mathrm{b}^{*}$ levels $(r=0.960, p<0.01 ; r=-0.871, p<0.01$ and $r=-0.936, p<0.01$, respectively). In final products, moo som inoculated with KL102 had lower CIE L*and $\Delta \mathrm{E}$ and higher CIE a* values than those inoculated with TISIR543 $(p<0.05)$. CIE L* values increased, resulting from protein denaturation induced by acid formed during fermentation in which a higher amount of CIE L* values were related to their higher total acid levels $(r=0.915, p<0.01)$. The redness of Thai fermented sausage is mostly accredited to nitrosylmyoglobin (pink). It is the common pigment of uncooked cured meat [38]. During fermentation, quantification of many myoglobin forms in Thai fermented sausage described that nitric oxide myoglobin was instinctively formed in fermented sausage during the mixing of raw mixture and was recorded in approximately $90 \%$ of total heme pigment [39]. In addition, oxidative discoloration of fermented sausages is characterized by conversion of nitrosylmyoglobin to nitrate and the brown 
http://wjst.wu.ac.th

derivative metmyoglobin; this quality-deteriorating process is known to depend on partial oxygen pressure and myoglobin reducing systems in general, and is most likely related to subsequent lipid oxidation [40]. Color of fermented meat was reported to conduce to consumer acceptability [36].

Effect of inoculation KL102 on texture and sensory evaluation of moo som at end of fermentation

At the end of fermentation, the results of the texture profile analysis are indicated in Table 2 . In the final products $(\mathrm{pH}<4.6)$, moo som inoculated with KL102 had higher hardness, gumminess, and chewiness than other moo som samples $(p<0.05)$. On the other hand, no differences in cohesiveness and springiness were found between all samples $(p>0.05)$. The hardness of fermented sausage is a measure of maturation and might be a result of denaturation and gelation of muscle proteins and the loss of water [36]. This result found that there was a significant negative correlation of released water vs hardness, gumminess, and chewiness $(r=-0.997, p<0.01 ; r=-0.985, p<0.01$, and $r=-0.986, p<0.01$, respectively). A decrease in $\mathrm{pH}$ during moo som fermentation influenced the formation changes of muscle proteins and caused the acid-induced gelation. Due to lower $\mathrm{pH}$ value, the textural improvement of moo som inoculated with KL102 was more proclamatory. According to correlation among tested variables, there was a significant negative correlation of $\mathrm{pH}$ vs hardness, gumminess, and chewiness of final products $(r=-0.951, p<0.01 ; r=-0.888, p<0.05$, and $r=-0.889, p<0.05$, respectively).

Table 2 Texture profile analysis of moo som inoculated with TISIR543 and KL102 at end of fermentation $^{1,2}$.

\begin{tabular}{lrrrrc}
\hline Variables & \multicolumn{1}{c}{ Control } & \multicolumn{1}{c}{ TISIR543 } & \multicolumn{1}{c}{ KL102 } & SEM $^{\mathbf{3}}$ & $\boldsymbol{p}_{\text {-value }}$ \\
\hline Hardness (N) & $27.63 \pm 1.62^{\mathrm{C}}$ & $34.91 \pm 1.46^{\mathrm{B}}$ & $37.64 \pm 1.79^{\mathrm{A}}$ & 1.63 & 0.01 \\
Cohesiveness (ratio) & $0.57 \pm 0.02^{\mathrm{A}}$ & $0.58 \pm 0.01^{\mathrm{A}}$ & $0.59 \pm 0.02^{\mathrm{A}}$ & 0.01 & 0.07 \\
Gumminess (N) & $15.79 \pm 0.86^{\mathrm{C}}$ & $19.57 \pm 1.51^{\mathrm{B}}$ & $22.31 \pm 1.03^{\mathrm{A}}$ & 1.16 & 0.01 \\
Springiness (ratio) $^{\mathrm{A}}$ & $0.90 \pm 0.03^{\mathrm{A}}$ & $0.91 \pm 0.01^{\mathrm{A}}$ & $0.92 \pm 0.01^{\mathrm{A}}$ & 0.02 & 0.10 \\
Chewiness (N) $^{\mathrm{C}}$ & $15.77 \pm 0.87^{\mathrm{C}}$ & $19.58 \pm 1.52^{\mathrm{B}}$ & $22.31 \pm 1.01^{\mathrm{A}}$ & 1.16 & 0.01 \\
\hline
\end{tabular}

${ }^{1}$ Values are mean \pm SD from triplicate determinations.

${ }^{2}$ Different uppercase letters within the same variable indicate significant differences sample $(p<0.05)$.

${ }^{3} \mathrm{SEM}$ is standard error of mean.

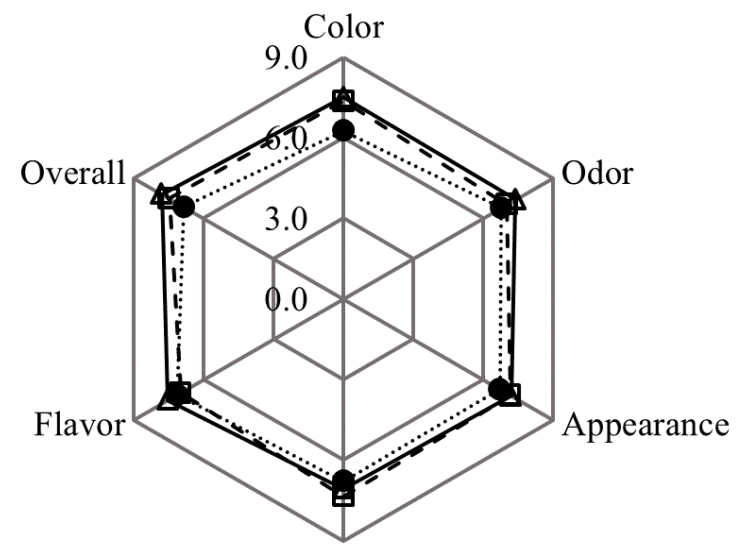

Texture

Control ÐTISTR543 $\triangle$ KL102

Figure 6 Sensory evaluation of moo som inoculated with different inoculum of L. plantarum (noninoculum [control], TISTR543, and KL102) at the end of fermentation. 
http://wjst.wu.ac.th

The sensory evaluation exposed significant $(p>0.05)$ differences in some of the sensory variables of the final products (Figure 6). Moo som inoculated with starter cultures had higher color and overall scores than moo som without inoculation $(p<0.05)$. The observed differences in the instrumental analysis of color were less considerable in the sensory evaluation, which only indicated a lower CIE L* and $\Delta \mathrm{E}$ in the moo som inoculated with starter culture. A higher color of sensorial analysis might relate to their lower amounts of CIE $\mathrm{L}^{*}$ and $\Delta \mathrm{E}(r=-0.919, p<0.01$ and $r=-0.759, p<0.07$, respectively). Furthermore, a higher overall score was related to their higher scores for color, odor and texture $(r=$ $0.972, p<0.01 ; r=0.960, p<0.01 ; r=0.962, p<0.01$, respectively). However, for odor, appearance, texture, and flavor, the differences between all samples were not significant $(p>0.05)$. This was probably due to the inoculation with low LAB starter concentration in the moo som, which was associated with the odor, texture and flavor of fermented meat [36]. These results of the sensory evaluation appeared to confirm the positive effect of the action of the starter cultures in controlling the fermentation.

\section{Conclusions}

The results distinctly indicated that moo som had naturally higher spoilage and pathogenic bacteria loading, and lower color and overall scores. In contrast, inoculations with LAB starter may lead to the development of microbiological (yeast, $S$. aureus, and coliform) and physicochemical qualities and sensory evaluation of moo som fermentation which results in higher color and overall scores in the final products. Thus, for better microbiological safety concerns, moo som should be produced by inoculation of KL102 as a starter culture.

\section{Acknowledgements}

The authors would like to thank the Faculty of Agricultural Technology, King Mongkut's Institute of Technology Ladkrabang, for the financial support.

\section{References}

[1] Thai Industrial Standards Institute. Thai Community Product Standard No. 876/2548: Moom-som (in Thai). Ministry of Industry, Thailand, 2005, p. 4.

[2] T Khieokhachee, W Praphailong, C Chowvalitnitithum, S Kunawasen, S Kumphati, V Chavasith, S Bhumiratana and R Valyasevi. Microbial interaction in the fermentation of Thai pork sausage. In: Proceedings of the $6^{\text {th }}$ ASEAN Food Conference, Singapore, 1997, p. 312-8.

[3] KV Paukatong and S Kunawasen. The hazard analysis and critical control points (HACCP) generic model for the production of Thai pork sausage (Nham). Berliner Und Munchener Tierarztliche Wochenschrift 2001; 114, 1-4.

[4] MR Adams and P Marteau. On the safety of lactic acid bacteria from food. Int. J. Food Microbiol. 1995; 27, 263-4.

[5] M Oliveira, V Ferreira, R Magalhães and P Teixeira. Biocontrol strategies for Mediterranean-style fermented sausages. Food Res. Int. 2018; 103, 438-49.

[6] CA Genigeorgis. Quality control for fermented meats. J. Am. Vet. Med. Assoc. 1976; 169, 81-93.

[7] P Rotsatchakul, W Visesanguan, T Smitinont and S Chaiseri. Changes in volatile compounds during fermentation of nham (Thai fermented sausage). Int. Food Res. J. 2009; 16, 391-414.

[8] P Luxananil, R Promchai, S Wanasen, S Kamdee, P Thepkasikul, V Plengvidhya, W Visessanguan and R Valyasevi. Monitoring Lactobacillus plantarum BCC 9546 starter culture during fermentation of Nham, a traditional Thai pork sausage. Int. J. Food Microbiol. 2009; 129, 312-5.

[9] A Tosukhowong, W Visessanguan, L Pumpuang, P Tepkasikul, A Panya and R Valyasevi. Biogenic amine formation in Nham, a Thai fermented sausage, and the reduction by commercial starter culture, Lactobacillus plantarum BCC 9546. Food Chem. 2011; 129, 846-53.

[10] A Swetwiwathana, K Pilasombut and J Sethakul. Screening of bacteriocin producing lactic acid bacteria isolated from Thai fermented meat for probiotic prospect. J. Biotechnol. 2008; 136, s737s738 
http://wjst.wu.ac.th

[11] A Swetwiwathana and W. Visessanguan. Potential of bacteriocin-producing lactic acid bacteria for safety improvements of traditional Thai fermented meat and human health. Meat Sci. 2015; 109, $101-5$.

[12] P Tangwatcharin, J Nithisantawakhup and K Suksuphath. Screening and selection for preliminary property of potential probiotic lactic acid bacteria from fermented meat products. King Mongkut's Agri. J. 2016; 34, 67-76.

[13] J Nithisantawakhupt, P Tangwatcharin and N Vijitrothai. Survival of lactic acid bacteria isolated from fermented meat products in gastrointestinal tract model. In: Proceedings of the $17^{\text {th }}$ AsianAustralasian Association of Animal Societies Animal Science Congress, Fukuoka, Japan, 2016, p. 1075-9.

[14] JC De man, M Rogosa and ME Sharpe. A medium for the cultivation of lactobacilli. Appl. Bacteriol. $1960 ; 23,130-5$.

[15] BAM. Staphylococcus aureus, Available at: https:/www.fda.gov/Food/FoodScienceResearch/ LaboratoryMethods/ucm071429.htm, accessed October 2017.

[16] BAM. Enumeration of Escherichia coli and the coliform bacteria in food. Available at: https://www.fda.gov/Food/FoodScienceResearch/LaboratoryMethods/ucm064948.htm, accessed November 2017.

[17] ISO 6579. Microbiology of Food and Animal Feeding Stuffs-Horizontal Method for the Detection. $4^{\text {th }}$ eds. International Organization for Standardization, Geneva, Switzerland, 2002, p. 9.

[18] AOAC. Official Methods of Analysis. $17^{\text {th }}$ ed. Association of Official Analytical Chemists, Gaithersburg, MD, USA, 2000, p. 2200.

[19] QH Lowry, NJ Rosebrough, LA Farr and RJ Randall. Protein measurement with the folin phenol reagent. J. Biol. Chem. 1951; 193, 256-75.

[20] UK Laemmli. Cleavage of structural proteins during the assembly of head of bacteriophage T4. Nature 1970; 277, 680-5.

[21] Y Nakao, A Konno, T Taguchi, T Tawada, H Kasai, J Toda and M Terasaki. Curdlan: Properties and application foods. J. Food Sci. 1991; 56, 769-72.

[22] AMSA. Guidelines for meat color evaluation. In: Proceedings of $44^{\text {th }}$ Reciprocal Meat Conference National Live Stock and Meat Board, Chicago, USA, 1991, p. 1-17.

[23] MC Bourne. Texture profile analysis. Food Technol. 1978; 32, 62-5.

[24] S Sorapukdee, C Uesakulrungrueng and K Pilasombut. Effects of humectant and roasting on physicochemical and sensory properties of jerky made from spent hen meat. Korean J. Food Sci. An. 2016; 36, 326-34.

[25] DD Gioia, G Mazzola, I Nikodinoska, I Aloisio, T Langerholc, M Rossi, S Raimondi, B Melero and J Rovira. Lactic acid bacteria as protective cultures in fermented pork meat to prevent Clostridium spp. growth. Int. J. Food Microbiol. 2016; 235, 53-9.

[26] CSM Regina, MG Delaine, MH Humberto, FS de Arthur and QS Amparo. Dynamics of the yeast flora in artisanal country style and industrial dry cured sausage (yeast in fermented sausage). Food Control. 2013; 29, 143-8.

[27] M Zagorec and MC Champomier-Vergès. Lactobacillus sakei: A starter for sausage fermentation, a protective culture for meat products. Microorganisms 2017; 5, 56.

[28] P Tremonte, G Pannella, M Succi, L Tipaldi, M Sturchio, R Coppola, D Luongo and E Sorrentino. Antimicrobial activity of Lactobacillus plantarum strains isolated from different environments: A preliminary study. Int. Food Res. J. 2017; 24, 852-9.

[29] G Burgé, C Saulou-Bérion, M Moussa, F Allais, V Athes and HE Spinnler. Relationships between the use of Embden Meyerhof pathway (EMP) or Phosphoketolase pathway (PKP) and lactate production capabilities of diverse Lactobacillus reuteri strains. J. Microbiol. 2015; 53, 702-10.

[30] K Chadong, S Yunchalard and W Piyatheerawong. Physicochemical characteristics and protein degradation during fermentation of Plaa-som, A traditional fermented fish product of North-Eastern Thailand. Indian J. Tradit. Know. 2015; 14, 220-5.

[31] W Sriphochanart and W Skolpap. Characterization of proteolytic effect of lactic acid bacteria starter cultures on Thai fermented sausages. J. Food Biotechnol. 2010; 24, 293-311. 
http://wjst.wu.ac.th

[32] M Laranjo, M Elias and MJ Fraqueza. The use of starter cultures in traditional meat products. $J$. Food Quality 2017; 2017, 9546026.

[33] DY Wang, MH Zhang, H Bian, H Dong, WM Xu, XL Xu, YZ Zhu, F Liu, ZM Geng, GH Zhou and $\mathrm{P}$ Wang. Proteolysis and cathepsin activities in the processing of dry-cured duck. Poult. Sci. 2014; 93, 678-94.

[34] S Fadda, MJ Vildoza and G Vignolo. The acidogenic metabolism of Lactobacillus plantarum CRL 681 improves sarcoplasmic protein hydrolysis during meat fermentation. J. Muscle Foods. 2010; 21, 545-56.

[35] S Freiding, KA Gutsche, MA Ehrmann and RF Vogel. Genetic screening of Lactobacillus sakei and Lactobacillus curvatus strains for their peptidolytic system and amino acid metabolism, and comparison of their volatilomes in a model system. Syst. Appl. Microbiol. 2011; 34, 311-20.

[36] F Toldrá. Handbook of Fermented of Meat and Poultry. Wiley Blackwell, West Sussex, UK, 2014, p. 528.

[37] D Demeyer. Meat Fermentaion: Principle and Applications. In: YH Hui (Ed.). Handbook of Food Science, Technology and Engineering. Vol. II. CRC Press, Boca Raton, FL, 2006, p. 65-8.

[38] A Wanangkarn, DC Liu, A Swetwiwathana and FJ Tan. An innovative method for the preparation of mum (Thai fermented sausages) with acceptable technological quality and extended shelf-life. Food Chem. 2012; 135, 515-21.

[39] M Karwowska1 and ZJ Dolatowski. Effect of acid whey and freeze-dried cranberries on lipid oxidation and fatty acid composition of nitrite-/nitrate-free fermented sausage made from deer meat. Asian-Australasian J. Anim. Sci. 2017; 30, 85-93.

[40] J Gøtterup, K Olsen, S Knøchel, K Tjener, LH Stahnke and JKS Møller. Colour formation in fermented sausages by meat-associated staphylococci with different nitrite- and nitrate-reductase activities. Meat Sci. 2008; 78, 492-501. 